\title{
METAL OXIDE NANOSTRUCTURE-BASED GAS SENSOR FOR CARBON DIOXIDE DETECTION
}

\author{
V. Gerbreders, M. Krasovska, I. Mihailova*, J. Kostjukevics, \\ E. Sledevskis, A. Ogurcovs, A. Gerbreders, A. Bulanovs \\ Institute of Life Sciences and Technology, Daugavpils University, \\ 1 Parades Str., Daugavpils, LV-5401, LATVIA \\ *e-mail: irena.mihailova@du.Iv
}

To increase the sensitivity and efficiency of a gas sensor, nanostructured $\mathrm{ZnO}$ and $\mathrm{Co}_{3} \mathrm{O}_{4}$ layers were obtained by hydrothermal synthesis directly on the electrode surface, eliminating the use of binders. Scanning electron microscope images showed that the resulting nanostructured coatings were characterised by good adhesion to the surface and high porosity, which opened up the possibility of their further use in the process of developing a gas sensor. The efficiency of the obtained nanostructured coatings and their sensitivity at room temperature to various concentrations of $\mathrm{CO}_{2}$ were determined. The resistance curves of the samples were obtained as a function of gas concentration in the chamber, for $\mathrm{Co}_{3} \mathrm{O}_{4}$ and $\mathrm{ZnO}$ nanostructures.

Keywords: Cobalt oxide, gas sensors, metal oxides, nanowires.

\section{INTRODUCTION}

Increasing demands for environmental protection and requirements for more efficient production management have promoted the development of various types of gas sensors [1], the most popular of which are chemical sensors [2]-[4]. The most important function of these sensors for human health is monitoring the quality of atmospheric air, and measuring air composition changes [5]-[8]. Due to spatial con- straints of the measurements, portable gadgets can quickly and most accurately define air composition and measure its change [9], [10]. For this purpose, gadgets based on metal oxides are widely used [11]-[15]. These sensors are resistive, wherein the electrical conductivity of the polycrystalline semiconductor film changes over time, according to gas concentration. Depending on the type of gas and the type of sensor 
conductivity (p-type or n-type), the resistance of the sensitive layer changes [16][23].

In some cases, for the development of this type of sensor, it is necessary to use additional heaters, as the process of chemisorption on a semiconductor surface can be dependent on temperature [24]-[27].

The signal of a resistive gas sensor is the integral magnitude, which corresponds to the content of different gases in the atmosphere, either oxidants or reductants. The process of interaction of sensing materials with gases includes: adsorption; surface chemical reactions; mutual diffusion of the components into the crystallites of the semiconductor; and desorption of the reaction products [28]. Chemisorption and reaction on semiconducting metal oxide surface lead to a change in concentration of charge carriers on the surface layer of the semiconductor. The transformation of the chemical signal (charge carrier concentration change on the surface) into integral conductivity of the sensing material is provided by transport of charge carriers [29][31]. The microstructure of the sensitive layer (particle size, existence and size of intracrystalline bridges, diameter and value of the pores, unit surface area) affects both processes on the surface and transport of charge carriers. It is expected that semiconducting nanostructured metal oxides show highly sensitive electrophysical properties and reactivity. This occurs due to much more developed surface area and larger number of active bonds of nanostructured coatings compared to smooth surfaces [32].

Recently, screen printing has been one of the most common methods of preparation of nanostructured electrodes [33]-[37]. This method involves the nanostructure preparation as powder, then mixing the powder with a binder that provides adhesion to the surface. The obtained mixture is coated on the electrode surfaces via a specific sieve. This method is simple and allows for the production of electrodes with different sizes and shapes; however, it has some disadvantages, such as the necessity to use polymers as binders. The polymer structures prevent the formation of highly porous films and limit the diffusion of the detected gas in the sensing layer.

Limitation of diffusion substantially decreases the working area of the electrode, and consequently leads to a reduction in sensitivity. This problem may be resolved by the use of the hydrothermal synthesis method, wherein the nanostructures grow directly on the surface of the electrode [38]. The growth of the nanostructures occurs via physical and chemical processes in aqueous solutions, at temperatures lower than $100{ }^{\circ} \mathrm{C}$. Due to the relatively low temperature of the process, there are many options for substrate materials: any chemically inactive surface can be coated by the nanostructures, including textiles and plastics. The hydrothermal method surpasses other methods in terms of diversity of the obtained morphologies: shape, size and nanostructure orientation can be changed by variation of the growing conditions, such as concentration and compound of the reagents, $\mathrm{pH}$ of the reaction media, and temperature and time of growth [39], [40].

Cobalt oxide $\left(\mathrm{Co}_{3} \mathrm{O}_{4}\right)$ is a p-type semiconductor. Generally, this type of conductivity in metal oxides exists due to excess oxygen in the crystal structure (oxygen atoms can substitute some metal atoms, or may be situated in internodes). Thus, there are inner accepting states which form positive charge carriers (holes) after capturing electrons. In an air environment, the surface of the semiconductor can adsorb additional particles of oxygen (localised external acceptor states), and this process increases the concentration of charge carriers (holes) near the sur- 
face, i.e., it forms a layer where the holes are accumulated. Gaseous oxidants, such as $\mathrm{O}_{2}, \mathrm{O}_{3}$ or $\mathrm{NO}_{2}$, enhance this effect, whereas gaseous reductants, such as $\mathrm{CO}, \mathrm{H}_{2}$ or $\mathrm{CH}_{4}$, affect the system by decreasing the amount of negative charge carriers, leading to a decrease in conductivity [41], [42].

It is known that the chemisorption and desorption of oxygen significantly affect the conductivity of sensing nanomaterials. In air, there is a large concentration of $\mathrm{O}_{2}$ molecules, which adsorb on the metal oxide (n-type) semiconductor surface. The $\mathrm{O}_{2}$ molecules capture electrons from the conduction band and become $\mathrm{O}^{2-}$ ions. As a result of this process, an electric field develops near the semiconductor surface. This field reduces the number of free electrons, forming a near-surface impoverished layer. In the case of a reduction in $\mathrm{O}_{2}$ (e.g., air pumping out of the system), the concentration gradient rises near the n-type semiconductor surface. In this case, the concentration of chemisorbed oxygen on the semiconductor surface layer becomes higher than in the outside atmosphere, and the $\mathrm{O}_{2}$ molecules would desorb from the semiconductor surface layer into the outside atmosphere. The captured electrons would, thus, be released from the $\mathrm{O}^{2-}$ ions and return to the conduction band, increasing the density of charge carriers. Under a continuous decrease in pressure, more $\mathrm{O}_{2}$ molecules will be released, decreasing the thickness of the impoverished surface layer. As a result, the resistance of the sensor element will decrease, and conductivity will grow, accordingly [42], [43]. The opposite effect would be observed if a p-type semiconductor were used as the sensor. During the pumping out of air, the released electrons would recombine with holes, decreasing the density of charge carriers. As the pressure decreases, the conductivity of the sample increases, accordingly.

Resistive sensors with p-type conductivity can have much more favourable characteristics, particularly degree of sensitivity. For n-type semiconductors, the surface and volume components of the conductivity are defined by the same charge carriers (electrons). In the case of p-type semiconductors, the surface and volume components of the conductivity are defined by different type of charge carriers (electrons and holes), and, as a result of their recombination, the change in conductivity is more significant [44]. The interaction between $\mathrm{CO}_{2}$ and nanostructured surfaces allegedly occurs by a different mechanism than for $\mathrm{O}_{2}$ [30]. A $\mathrm{CO}_{2}$ molecule has more stable atomic structure, and does not have a free electron pair for bonding. At low temperatures, water molecules react with $\mathrm{CO}_{2}$ to form carbonate $\left(\mathrm{CO}_{3}{ }^{2-}\right)$ ions on the metal oxide surface via several intermediate products, including bicarbonate ions (Eqs. (1)-(4)) [45], [46]. At high temperatures, $\mathrm{CO}_{2}$ molecules react with surface $\mathrm{O}^{2-}$ ions directly to form $\mathrm{CO}_{3}{ }^{2-}$ ions without intermediate products (Eq. (5)) [47]. Thus, the consumption of electrons by $\mathrm{CO}_{2}$ molecules during interaction with metal oxide surfaces leads to a decrease in film conductivity, and can be used for $\mathrm{CO}_{2}$ detection.

$$
\begin{aligned}
& \mathrm{CO}_{2(\text { gas })}+\mathrm{OH}_{(\text {adsorbed })}^{-} \leftrightarrow \mathrm{HCO}_{3(\text { surface }) .}^{-} \\
& \mathrm{CO}_{2(\text { gas })}+\mathrm{H}_{(\text {adsorbed })}^{+}+2 e_{(\text {surface })}^{-} \rightarrow \mathrm{HCO}_{2(\text { surface }) .}^{-} \\
& \mathrm{HCO}_{2(\text { surface })}^{-} \rightarrow \mathrm{CO} \uparrow+\mathrm{OH}_{(\text {surface }) .}^{-}
\end{aligned}
$$


$\mathrm{HCO}_{3(\text { surface })}^{-}+\mathrm{OH}^{-}{ }_{(\text {adsorbed })} \leftrightarrow \mathrm{CO}_{3}^{2-}{ }_{(\text {bulk })}+\mathrm{H}_{2} \mathrm{O}_{(\text {gas })}$.

$\mathrm{CO}_{2(\text { gas })}+\mathrm{O}_{(\text {adsorbed })}^{2-} \rightarrow \mathrm{CO}_{3}^{2-}$.

The aim of this study was to obtain porous and nanostructured films of cobalt and zinc oxides via hydrothermal meth- ods, and to examine the film efficiencies as working electrodes in $\mathrm{CO}_{2}$ gas sensors, at room temperature.

\section{METHODS AND MATERIALS}

Pectinate-type electrodes were used as a base. The electrodes were deposited on glass surfaces via magnetron spattering though a thin chrome mask (Kurt J. Lesker). The electrode dimensions were $1.0 \times 1.5 \mathrm{~cm}$.

For increasing nanostructured film adhesion and ordering in the coating, the chrome electrodes were first coated with a seed layer. For the $\mathrm{Co}_{3} \mathrm{O}_{4}$ seed layer formation, a $0.005 \mathrm{M}$ solution of $\left(\mathrm{CH}_{3} \mathrm{COO}\right)_{2} \mathrm{Co} \bullet 4 \mathrm{H}_{2} \mathrm{O}$ (98\% pure, purchased from SigmaAldrich) in ethanol (99.5\% pure, purchased from Chempur) was used as the precursor, and coated onto the electrode by a dipping method. Excess solution was removed by flowing nitrogen stream. Afterwards, the samples were placed in an oven at $350{ }^{\circ} \mathrm{C}$ for $20 \mathrm{~min}$, where thermal decomposition of the $\left(\mathrm{CH}_{3} \mathrm{COO}\right)_{2} \mathrm{Co} \bullet 4 \mathrm{H}_{2} \mathrm{O}$ layer to form $\mathrm{Co}_{3} \mathrm{O}_{4}$ occurred. The seed layer of $\mathrm{ZnO}$ was prepared using the same method. A 0.005 M solution of $\mathrm{Zn}\left(\mathrm{CH}_{3} \mathrm{COO}\right)_{2} \cdot 2 \mathrm{H}_{2} \mathrm{O}(98 \%$ pure, purchased from Sigma-Aldrich) in ethanol was used as the precursor. Annealing was carried out at $250^{\circ} \mathrm{C}$ for $20 \mathrm{~min}$.

For the growth of nanostructures, the samples were placed in a stainless steel holder, with the seed layer downside. This positioning was used in order to protect the working surfaces from interaction with collateral nanoparticles, which fall as precipitates during the chemical reaction. The holder with the samples was deposited in heat-resistant glass with a cover, and filled with the working solution. The growth process was carried out in an oven under the following conditions:

- For $\mathrm{Co}_{3} \mathrm{O}_{4}$ nanostructures, an equimolar aqueous solution $0.1 \mathrm{M}$ in $\mathrm{Co}\left(\mathrm{NO}_{3}\right)_{2} \cdot 6 \mathrm{H}_{2} \mathrm{O}$ (98\% pure, purchased from Sigma-Aldrich) and $0.1 \mathrm{M}$ in carbamide $\left(\mathrm{CH}_{4} \mathrm{~N}_{2} \mathrm{O}\right)(98 \%$ pure, purchased from Sigma-Aldrich) was used. The oven temperature was $95{ }^{\circ} \mathrm{C}$, and exposure time was $5 \mathrm{~h}$. Afterwards, the samples were washed several times with distilled water, and dried under a flowing nitrogen stream. The samples were then annealed at $450{ }^{\circ} \mathrm{C}$ for $1 \mathrm{~h}$. The annealing process could be verified visually by the colour change of the films, from pink to black.

- For $\mathrm{ZnO}$ nanostructures, an equimolar aqueous solution $0.1 \mathrm{M}$ in $\mathrm{Zn}\left(\mathrm{NO}_{3}\right)_{2}(98 \%$ pure, purchased from Sigma-Aldrich) and $0.1 \mathrm{M}$ in hexamethylenetetramine $\left(\mathrm{CH}_{2}\right)_{6} \mathrm{~N}_{4}(98 \%$ pure, purchased from Sigma-Aldrich) was used. The oven temperature was $90{ }^{\circ} \mathrm{C}$ and exposure time was $3 \mathrm{~h}$. Afterwards, the samples were washed several times with distilled water, and dried under a flowing nitrogen stream. As a result, white matt films were observed.

Smooth thin films of cobalt oxides were deposited on glass substrate via magnetron sputtering (Kurt J. Lesker). As a target, 
$99.9 \%$ purity Co was used. The process was conducted in oxygen-argon atmosphere (20\% $\mathrm{O}_{2} / 80 \% \mathrm{Ar}$ ), using $300 \mathrm{~W}$ discharge power and a sputtering time of $15 \mathrm{~min}$. As a result, the thickness of the films was 500 nm.

The surface morphology of the samples was studied using a scanning electron microscope (TESCAN-Maya3). The chemical composition of the samples was determined using an INCA x-act energy dispersive spectrometer (Oxford Instruments). To determine the sample structure and phase composition, X-Ray Diffraction (XRD) spectra were recorded using a SmartLab $\mathrm{Cu}$ $\mathrm{K} \alpha(\lambda=1.543 \AA)$ diffractometer (RIGAKU) with parallel beam geometry, using an additional $\mathrm{Ge}(220) \times 2$ monochromator.

Measurements of the dependence of electric resistance of the $\mathrm{Co}_{3} \mathrm{O}_{4}$ film samples on gas mixture composition (and pressure) were conducted in a specialised chamber (Kurt J. Lesker), at room temperature (21 ${ }^{\circ} \mathrm{C}$ ) and relative humidity of $26 \%$. During the measurement, air was pumped out (pressure reduction from atmospheric [760 Torr] to 0.1 Torr), and then atmospheric air was pumped back into the chamber. The same experiments were performed using other gases, namely $\mathrm{CO}_{2}$ and $\mathrm{O}_{2}(99 \%$ pure, purchased from Linde). During the pumping processes, measurements of pressure and electrical resistance of all nanostructured films were conducted.

In the following experiments, the dependence of the sample resistance on the $\mathrm{CO}_{2}$ concentration in the gas mixture was determined. Air from the chamber was pumped out down to 0.1 Torr, and then atmosphere air was pumped into a calculated pressure $\mathrm{P}_{\text {air }}$. The pressure $\mathrm{P}_{\text {air }}$ was lower than atmospheric, and the pressure difference was compensated for by pumping $\mathrm{CO}_{2}$ into the chamber until pressure reached 760 Torr. Experiments were conducted for air- $\mathrm{CO}_{2}$ mixtures using $\mathrm{CO}_{2}$ mass fractions ranging from 0.001 to 10,000 , corresponding to molar (volume) concentrations of $\mathrm{CO}_{2}$ of 650 to $997000 \mathrm{ppm}$. During the pumping processes, the resistance of the nanostructured samples of $\mathrm{Co}_{3} \mathrm{O}_{4}$ and $\mathrm{ZnO}$ was measured. To determine the nanostructured film relative efficiency, resistance measurements of the plain $\mathrm{Co}_{3} \mathrm{O}_{4}$ film were also conducted.

\section{RESULT AND DISCUSSION}

The SEM images and X-ray diffraction graph of the $\mathrm{Co}_{3} \mathrm{O}_{4}$ nanostructures are shown in Fig. 1.
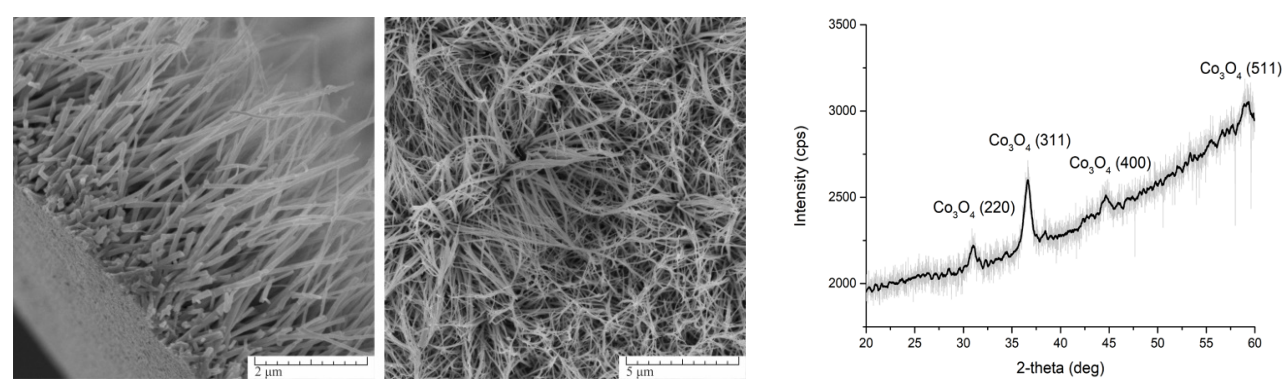

Fig. 1. SEM images and X-ray diffraction graph of $\mathrm{Co}_{3} \mathrm{O}_{4}$. 
Figure 1 shows that the $\mathrm{Co}_{3} \mathrm{O}_{4}$ film consists of vertical, oriented, long (about 5 $\mu \mathrm{m})$ strip-type nanostructures. Due to their small thickness relative to their length, the nanostructures lose their vertical alignment during their last stage of growth. Also, possibly due to their weight, the stripes lay chaotically, intertwining and forming a complicated net of porous labyrinths. The $\mathrm{X}$-ray diffraction analysis did not show any other compounds besides $\mathrm{Co}_{3} \mathrm{O}_{4}$. It can be observed on the diffraction graph that the sample has a high amorphous background and relatively low peak intensity. This is characteristic of nanostructures obtained by the use of carbamide, as observed in previous studies [48].

The SEM images and X-ray diffraction graph of the $\mathrm{ZnO}$ structures are shown in Fig. 2.
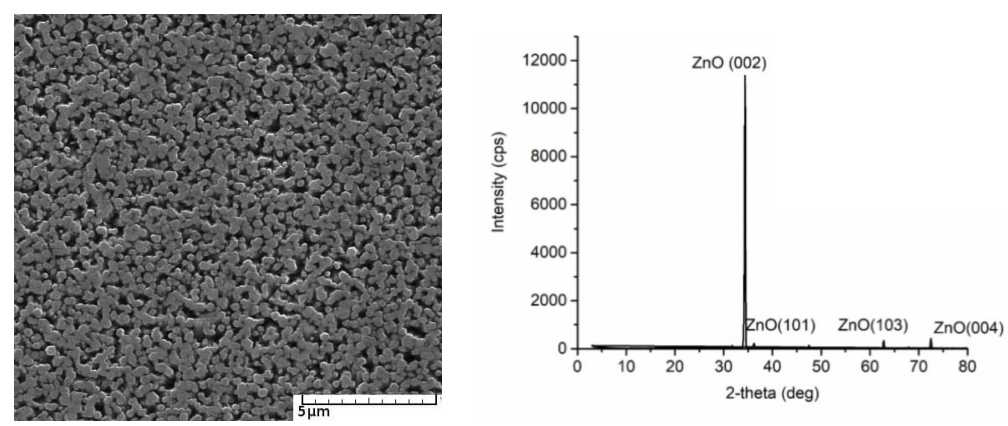

Fig. 2. SEM images and X-ray diffraction graph of $\mathrm{ZnO}$.

The $\mathrm{ZnO}$ film consists of strictly ordered, vertically aligned nanorods with a distinctive hexagonal prism form, approximately $2 \mu \mathrm{m}$ in length. Due to the lower length-to-thickness ratio, relative to the $\mathrm{Co}_{3} \mathrm{O}_{4}$ nanostructures, the $\mathrm{ZnO}$ rods retain their vertical alignment during the entire growth process. However, it is clear that the porosity of the $\mathrm{ZnO}$ nanostructures is much lower than for $\mathrm{Co}_{3} \mathrm{O}_{4}$.
The X-ray diffraction analysis did not show any crystalline compounds besides $\mathrm{ZnO}$. On the diffraction graph, the distinctive peak corresponding to the (002) plane can be seen. The intensities of other peaks are significantly lower than the (002) peak, confirming the dominant orientation of the nanostructures in the vertical direction. The amorphous background of the film is low, indicating a high degree of crystallinity.

\section{Study of the Resistance Dependence of the $\mathrm{Co}_{3} \mathrm{O}_{4}$ Samples on Gas Mixture Composition and Concentration}

(a) 950

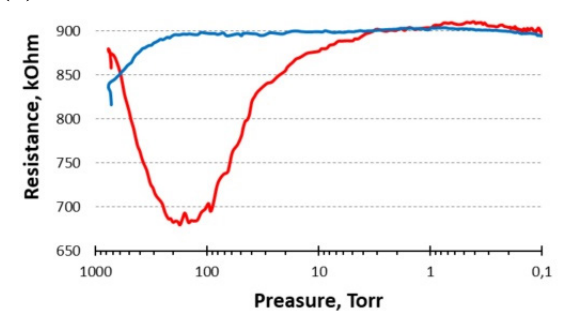

(b) 9

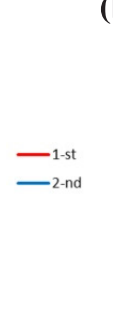

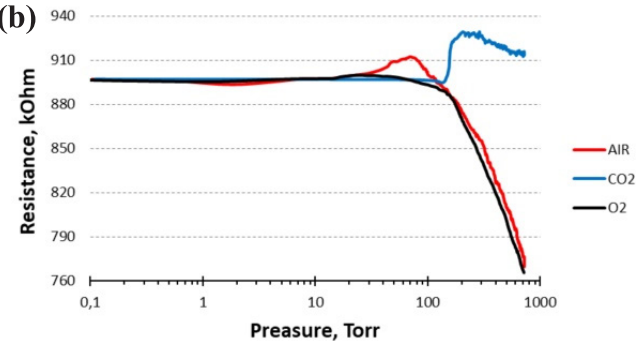

Fig. 3. (a) Dependence of $\mathrm{Co}_{3} \mathrm{O}_{4}$ sample resistance on gas pressure during air pumping from the chamber; (b) dependence of $\mathrm{Co}_{3} \mathrm{O}_{4}$ sample resistance on gas pressure during gas (air, $\mathrm{CO}_{2}, \mathrm{O}_{2}$ ) pumping into the chamber. 
During the first pumping-out of air, down to 175 Torr (Fig. 3(a), red line), the resistance of the sample significantly reduces (approximately $23 \%$ ). Afterwards, when the pressure reduced from 175 to 0.1 Torr, an increase in the sample resistance can be observed. The resistance "pit" in the graph may be explained by the release of adsorbed water and gas molecules from the sample surface. The increase in sample resistance as the pressure decreases further may be due to the same mechanism as described above; that is, the sensor sensitivity to the pressure of $\mathrm{O}_{2}$-containing gas atmospheres. During the pumping-out process, electrons which have been released during oxygen desorption recombine with holes. The amount of free charge carriers decreases, and the resistance grows.

During the second pumping-out process (Fig. 3(a), blue line), the same resistance pit is not observed - the sample does not adsorb atmospheric water, and only the oxygen desorption process influences the change in resistance. The plot shows an $11 \%$ increase in resistance during the first stage of the pumping-out process, and a relatively fast stabilisation of the resistance due to the equilibrium stage.

The pumping-in of $\mathrm{CO}_{2}$ to 0.1 Torr in the chamber (Fig. 3(b), blue line) leads to an increase in sample resistance up to $4 \%$. The mechanism of $\mathrm{CO}_{2}$ adsorption on the metal oxide nanostructures is as described in the introduction.

The pumping-in process of $\mathrm{O}_{2}$ to 0.1 Torr in the chamber (Fig. 3(b), black line) leads to a sharp decrease in sample resistance. This phenomenon may be explained by the formation of an ionic layer on the sample surface. $\mathrm{O}_{2}$ plays a major role in the adsorption process, due to its high electronegativity and electron pairs, which help it to adsorb on the surface. Diatomic oxygen molecules act as electron acceptors, going through an ionisation process and forming the ionic layer on the sample surface, assisting in the sorption of other gas molecules.

Electrons on the metal oxide surface act as the active centre for adsorption of atmospheric $\mathrm{O}_{2} \cdot \mathrm{O}_{2}$ from the environment diffuses to free sectors of $\mathrm{O}$ atoms on the metal oxide surface, accepting one or two free electrons. In this way, the chemisorption of $\mathrm{O}_{2}$ molecules decreases electron mobility, leading to a decrease in conductivity of the n-type materials, and diminishing the adsorption activity centre ability to further bind other particles from the atmosphere.

The pumping-in process of air up to 0.1 Torr in the chamber (Fig. 3(b), red line) leads to an increase in sample resistance up to $3 \%$, which later decreases to $15 \%$, relative to the starting resistance of the sample. This may be explained by the fact that air is a mixture of gases, containing both $\mathrm{O}_{2}$ and $\mathrm{CO}_{2}$. In this case, the adsorption of $\mathrm{CO}_{2}$ in the presence of $\mathrm{O}_{2}$ occurs. As mentioned previously, $\mathrm{O}_{2}$ additively promotes other molecule sorption into the system, and, thus, the distinctive $\mathrm{CO}_{2}$ peak can be observed at low concentrations of air during pumping-in. At high pressure, sorption of $\mathrm{O}_{2}$ becomes the dominant process, and the distinctive resistance decrease because $\mathrm{O}_{2}$ resembles the $\mathrm{O}_{2}$ pumping-in plot (Fig. 3(b), black line).

The dependence of relative change of sample resistance on $\mathrm{CO}_{2}$ amount, for both $\mathrm{Co}_{3} \mathrm{O}_{4}$ nanostructures and plain films, is shown in Fig. 4.

It can be seen that the nanostructured sample shows a higher relative resistance with higher $\mathrm{CO}_{2}$ amount than the plain film. The difference becomes especially distinctive at $\mathrm{m}_{\mathrm{co} 2} / \mathrm{m}_{\text {air }}=1$ and above, and the maximum ratio of $78 \%$. Higher performance of the nanostructured sample is explained by the difference in the working surface area. In the case of the plain film, the gas contacted only with the top of the surface, but 
in the nanostructured sample, the gas molecules penetrated between the nano-strips, and made contact with the pore surfaces, significantly increasing the amount of active bonds involved in the sorption process.

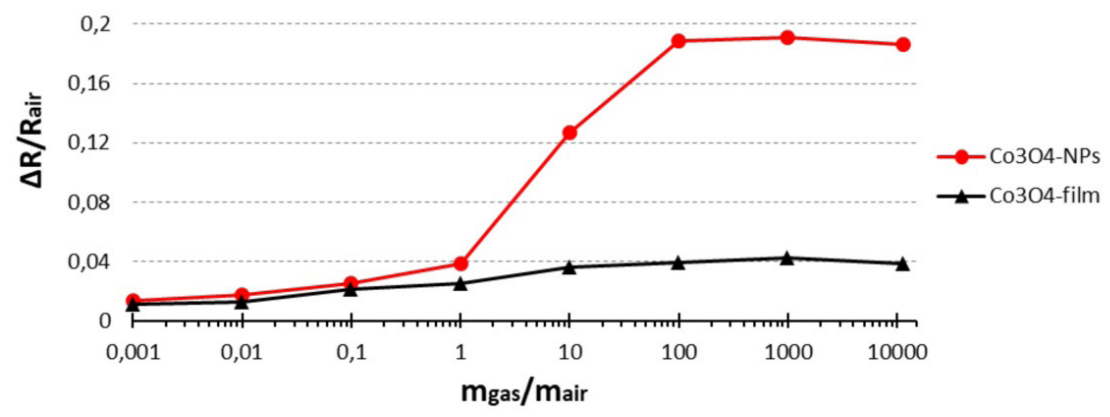

Fig. 4. Dependence of the relative change of different $\mathrm{Co}_{3} \mathrm{O}_{4}$ sample resistances on $\mathrm{CO}_{2}$ amount in the chamber.

Figure 5 demonstrates the dependence amount in the chamber for metal oxides of sample resistance changes on $\mathrm{CO}_{2}$ with different types of conductivity.

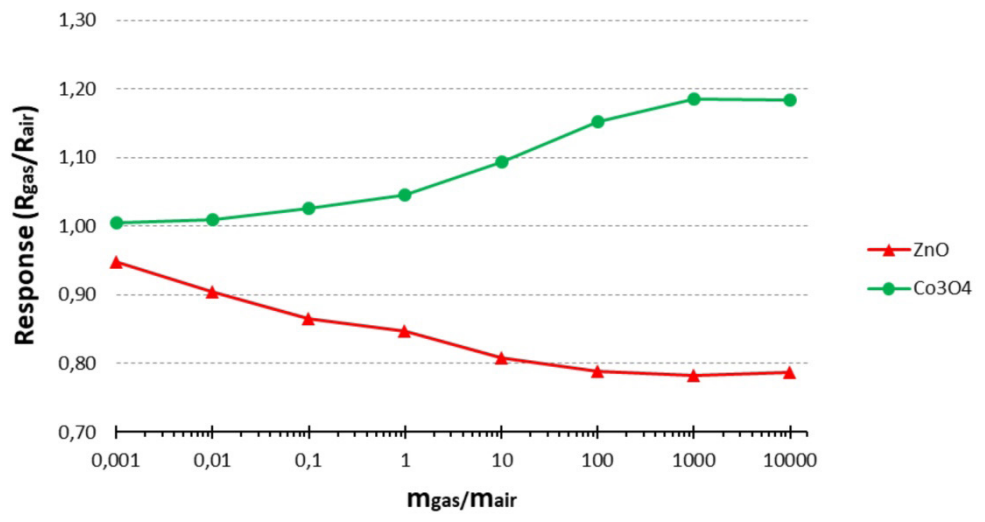

Fig. 5. Dependence of the relative change of the $\mathrm{Co}_{3} \mathrm{O}_{4}$ and $\mathrm{ZnO}$ sample resistances on $\mathrm{CO}_{2}$ amount in the chamber.

In the case of $\mathrm{Co}_{3} \mathrm{O}_{4}$ (p-type semiconductor), the resistance grows with an increase in $\mathrm{CO}_{2}$ amount, with the opposite trend occurring in the case of $\mathrm{ZnO}$ (n-type semiconductor). The curves confirm both of the mechanisms described above, namely, the mechanism of adsorption of $\mathrm{CO}_{2}$ for different type of semiconductors and the mechanism of changes of semiconduc- tor conductivity in the case of varying $\mathrm{O}_{2}$ concentration in the air-gas mixture. The response magnitudes for both samples are approximately the same. This indirectly proves that the sensor sensitivities do not depend on the material conductivity type, but are defined by the existence of nanostructures (sample porosity and total surface area). 
In this study, nanostructured samples of $\mathrm{Co}_{3} \mathrm{O}_{4}$ and $\mathrm{ZnO}$ were obtained by the hydrothermal method. The nanostructured samples showed a response to addition of $\mathrm{CO}_{2}$ to a gas chamber, and the response was dependent on pressure. These observed effects demonstrate the potential use of these materials as working elements of resistive gas sensors.

The nanostructured samples of $\mathrm{Co}_{3} \mathrm{O}_{4}$ demonstrate higher resistance changes during increasing $\mathrm{CO}_{2}$ concentration compared with smooth films of the same material, making the nanostructured material more attractive for sensor preparation.

\section{ACKNOWLEDGEMENTS}

This study has been supported by internal research grant No. 14-95/20 of Daugavpils University "Development of a
Gas Sensor Based on Cobalt Oxide Nanostructures".

\section{REFERENCES}

1. Korotchenkov, G. (2013). Handbook of gas sensor materials. New York: Springer. DOI:10.1007/978-1-4614-7165-3

2. Liu, X., Cheng, S, Liu, H., Hu, S., Zhang, D., \& Ning, H. (2012). A Survey on Gas Sensing Technology. Sensors, 12, 96359665. DOI: 10.3390/s120709635

3. Janata, J. (2009). Principles of chemical sensors. New York: Springer.

4. Joshi, N., Hayasaka, T., Liu, Y., Liu, H., Oliveira, O. N., \& Lin, L. (2018). A Review on Chemiresistive Room Temperature Gas Sensors Based on Metal Oxide Nanostructures, Graphene and 2D Transition Metal Dichalcogenides. Microchimica Acta, 185 (4), 185-213. DOI:10.1007/s00604-0182750-5

5. Kampa, M., \& Castanas, E. (2008). Human Health Effects of Air Pollution. Environmental Pollution, 151, 362-367. DOI: 10.1016/j.envpol.2007.06.012

6. Snyder, E. G., Watkins, T. H., Solomon, P. A., Thoma, E. D., Williams, R. W., ... \& Preuss, P. W. (2013). The Changing
Paradigm of Air Pollution Monitoring, Environmental Science \& Technology, 47, 11369-11377. DOI:10.1021/es4022602

7. Babadjouni, R., Hodis, D., Radwanski, R., Durazo, R., Patel, A., Liu, Q., \& Mack, W. (2017). Clinical Effects of Air Pollution on the Central Nervous System: A Review. Journal of Clinical Neuroscience, 43, 1624. DOI:10.1016/j.jocn.2017.04.028

8. Glencross, D., Ho, T., Camica, N., Hawrylowicz, C., \& Pfeffer, P. (2020). Air Pollution and its Effects on the Immune System. Free Radical Biology and Medicine, 151, 56-68. DOI:10.1016/j. freeradbiomed.2020.01.179

9. Lobur, M., Korpyljov, D., Jaworski, N., Iwaniec, M., \& Marikutsa, U. (2020). Arduino based ambient air pollution sensing system. In IEEE XVIth International Conference on the Perspective Technologies and Methods in MEMS Design (MEMSTECH), (pp. 32-35), 22-26 April 2020, Lviv, Ukraine: Lviv Polytechnic National University. DOI: 10.1109/ MEMSTECH49584.2020.9109460. 
10. Hasenfratz D., Saukh O., Sturzenegger S., \&Thiele L. (2012) Participatory air pollution monitoring using smartphones. In Proceedings of the 2nd International Workshop on Mobile Sensing, (pp. 1-5), 16-20 April 2012, Beijing, China.

11. Galstyan, V., Comini, E., Baratto, C., Faglia, G., \& Sberveglieri, G. (2015). Nanostructured ZnO Chemical Gas Sensors. Ceramics International, 41, 14239-14244. DOI:10.1016/j.ceramint.2015.07.052

12. Zhu, L., \& Zeng, W. (2017). RoomTemperature Gas Sensing of ZnO-Based Gas Sensor: A Review. Sensors and Actuators A, 267, 242-261. DOI:10.1016/j. sna.2017.10.021

13. Dey, A. (2018). Semiconductor Metal Oxide Gas Sensors: A Review. Materials Science \& Engineering B, 229, 206-217. DOI: 10.1016/j.mseb.2017.12.036

14. Yoon, J., Kim, H., Jeong, H., \& Lee, J. (2014). Gas Sensing Characteristics of P-Type $\mathrm{Cr} 2 \mathrm{O} 3$ and $\mathrm{Co} 3 \mathrm{O} 4$ Nanofibers Depending on Inter-Particle Connectivity. Sensors and Actuators B, 202, 263-271. DOI:10.1016/j.snb.2014.05.081

15. Moseley, P. T. (2017). Progress in the Development of Semiconducting Metal Oxide Gas Sensors: A Review. Measurement Science and Technology, 28 (8), 082001 (15 p.). DOI:10.1088/1361-6501/aa7443

16. Jing, Z., \& Zhan, J. (2008). Fabrication and Gas-Sensing Properties of Porous $\mathrm{ZnO}$ Nanoplates. Advanced Materials, 20 (23), 4547-4551. DOI:10.1002/adma.200800243

17. Liu, C., Zhao, L., Wang, B., Sun, P., Wang, Q., ...\& Lu, G. (2017). Acetone Gas Sensor Based on $\mathrm{NiO} / \mathrm{ZnO}$ Hollow Spheres: Fast Response and Recovery, and Low (ppb) Detection Limit. Journal of Colloid and Interface Science, 495, 207-215. DOI:10.1016/j.jcis.2017.01.106

18. Sonker, R. K., Sabhajeet, S. R., Singh, S., \& Yadav, B. C. (2015). Synthesis of $\mathrm{ZnO}$ Nanopetals and its Application as NO2 Gas Sensor. Materials Letters, 152, 189-191. DOI:10.1016/j.matlet.2015.03.112

19. Yu, L., Guo, F., Liu, S., Yang, B., Jiang,
Y., .. \& Fan, X. (2016). Both Oxygen Vacancies Defects and Porosity Facilitated NO 2 Gas Sensing Response in 2D ZnO Nanowalls at Room Temperature. Journal of Alloys and Compounds, 682, 352-356. DOI:10.1016/j.jallcom.2016.05.053

20. Zhu, L., \& Zeng, W. (2017). RoomTemperature Gas Sensing of ZnO-Based Gas Sensor: A Review. Sensors and Actuators A: Physical, 267, 242-261. DOI:10.1016/j.sna.2017.10.021

21. Yoon, J.-W., Kim, H.-J., Jeong, H.-M., \& Lee, J.-H. (2014). Gas Sensing Characteristics of p-Type $\mathrm{Cr} 2 \mathrm{O} 3$ and $\mathrm{Co} 3 \mathrm{O} 4$ Nanofibers Depending on Inter-Particle Connectivity. Sensors and Actuators B: Chemical, 202, 263-271. DOI:10.1016/j.snb.2014.05.081

22. Deng, S., Chen, N., Deng, D., Li, Y., Xing, X., \& Wang, Y. (2015). Meso- and Macroporous Coral-like Co3O4 for VOCs Gas Sensor. Ceramics International, 41 (9), 11004-11012.DOI:10.1016/j.ceramint.2015. 05.045

23. Zoolfakar, A. S., Ahmad, M. Z., Rani, R. A., Ou, J. Z., Balendhran, S., ... \& Kalantarzadeh, K. (2013). Nanostructured Copper Oxides as Ethanol Vapour Sensors. Sensors and Actuators B: Chemical, 185, 620-627. DOI:10.1016/j.snb.2013.05.042

24. Fine, G. F., Cavanagh, L. M., Afonja, A., \& Binions, R. (2010). Metal Oxide SemiConductor Gas Sensors in Environmental Monitoring. Sensors, 10 (6), 5469-5502. DOI:10.3390/s100605469

25. Wang, C., Yin, L., Zhang, L., Xiang, D., \& Gao, R. (2010). Metal Oxide Gas Sensors: Sensitivity and Influencing Factors. Sensors, 10 (3), 2088-2106. DOI:10.3390/ s100302088

26. Zhang, J., Liu, X., Neri, G., \& Pinna, N. (2015). Nanostructured Materials for Room-Temperature Gas Sensors. Advanced Materials, 28 (5), 795-831. DOI:10.1002/ adma. 201503825

27. Zhu, L., \& Zeng, W. (2017). A Novel Coral Rock-like $\mathrm{ZnO}$ and its Gas Sensing. Materials Letters, 209, 244-246. DOI:10.1016/j.matlet.2017.08.020 
28. Arregui, F. J. (ed.). (2009). Sensors based on nanostructured materials. New York: Springer. DOI:10.1007/978-0-387-77753-5

29. Fort, A., Panzardi, E., Vignoli, V., Hjiri, M., Aida, M., Mugnaini, M., \& Addabbo, T. (2019). Co3O4/Al-ZnO Nano-Composites: Gas Sensing Properties. Sensors, 19 (4), 760. doi:10.3390/s19040760

30. Shankar, P., \& Rayappan, J. (2015) Gas Sensing Mechanism of Metal Oxides: The Role of Ambient Atmosphere, Type of Semiconductor and Gases - A Review, Science Letters Journal, 4, 126, (18 p.). http://www.cognizure.com/scilett.aspx?p= 200638572

31. Yang, S., Jiang, C., \& Wei, S. (2017). Gas Sensing in 2D Materials. Applied Physics Reviews, 4 (2), 021304. DOI:10.1063/1.4983310

32. Krasovska, M., Gerbreders, V., Mihailova, I., Ogurcovs, A., Sledevskis, E., ... \& Sarajevs, P. (2018). ZnO-NanostructureBased Electrochemical Sensor: Effect of Nanostructure Morphology on the Sensing of Heavy Metal Ions. Beilstein Journal of Nanotechnology, 9, 2421-2431. DOI:10.3762/bjnano.9.227

33. Azeez, O. A., Sabry, R. S., Hassan, M. A. M., \& Madlul, S. F. (2015). Synthesis and Characteristics of Screen Printed $\mathrm{ZnO}$ Thick Films Nanostructures Grown Using Different Methods. Journal of Materials Science: Materials in Electronics, 26 (6), 4051-4061. DOI:10.1007/s10854-015-2944-0

34. Ferraz, H. C., Machado, D. F., \& de Resende, N. S. (2017). Nanostructured Screen-Printed Electrodes Based on Titanate Nanowires for Biosensing Applications. Materials Science and Engineering: C, 70, 15-20. DOI:10.1016/j.msec.2016.08.046

35. Sarkar, K., Braden, E. V., Bonke, S. A., Bach, U., \& Müller-Buschbaum, P. (2015). Screen-Printing of $\mathrm{ZnO}$ Nanostructures from Sol-Gel Solutions for their Application in Dye-Sensitized Solar Cells. ChemSusChem, 8 (16), 2696-2704. DOI:10.1002/cssc. 201500450
36. Carotta, M. C., Martinelli, G., Crema, L., Malagù, C., Merli, M., ... \&Traversa, E. (2001). Nanostructured Thick-Film Gas Sensors for Atmospheric Pollutant Monitoring: Quantitative Analysis on Field Tests. Sensors and Actuators B: Chemical, 76 (1-3), 336342. DOI:10.1016/s0925-4005(01)00620-7

37. Solis, J. ., Saukko, S., Kish, L., Granqvist, C., \& Lantto, V. (2001). Semiconductor Gas Sensors Based on Nanostructured Tungsten Oxide. Thin Solid Films, 391 (2), 255-260. DOI:10.1016/s0040-6090(01)00991-9

38. Zhou, Q., Chen, W., Xu, L., \& Peng, S. (2013). Hydrothermal Synthesis of Various Hierarchical ZnO Nanostructures and their Methane Sensing Properties. Sensors, 13 (5), 6171-6182. DOI:10.3390/s130506171

39. Mihailova, I., Gerbreders, V., Bulanovs, A., Tamanis, E., Sledevskis, E., ... \& Sarajevs, P. (2014). Controlled growth of well-aligned $\mathrm{ZnO}$ nanorod arrays by hydrothermal method. In the 8th International Conference on Advanced Optical Materials and Devices (AOMD-8), (9421-23), 25-27 August 2014, Riga, Latvia.

40. Krasovska, M., Gerbreders, V., Paskevics, V., Ogurcovs, A., \& Mihailova, I. (2015). Obtaining a Well-Aligned $\mathrm{ZnO}$ Nanotube Array Using the Hydrothermal Growth Method. Latvian Journal of Physics and Technical Sciences, 52 (5), 28-40. DOI:10.1515/lpts-2015-0026

41. Mokoena, T. P., Swart, H. C., \& Motaung, D. E. (2019). A Review on Recent Progress of p-Type Nickel Oxide Based Gas Sensors: Future Perspectives. Journal of Alloys and Compounds, 267-294. DOI:10.1016/j. jallcom.2019.06.329

42. Kim, H.-J., \& Lee, J.-H. (2014). Highly Sensitive and Selective Gas Sensors Using p-Type Oxide Semiconductors: Overview. Sensors and Actuators B: Chemical, 192, 607-627. DOI:10.1016/j.snb.2013.11.005

43. Ji, H., Zeng, W., \& Li, Y. (2019). Gas Sensing Mechanisms of Metal Oxide Semiconductors: A Focus Review. Nanoscale, 11, 22664-22684. DOI:10.1039/ c9nr07699a 
44. Barsan, N., Simion, C., Heine, T., Pokhrel, S., \& Weimar, U. (2010). Modelling of Sensing and Transduction for p-Type Semiconducting Metal Oxide Based Gas Sensors. Journal of Electroceramics, 25 (1), 11-19. DOI:10.1007/s10832-009-9583-x

45. Wurzinger, O., \& Reinhardt, G. (2004). $\mathrm{CO}$-sensing Properties of Doped $\mathrm{SnO} 2$ Sensors in H2-rich Gases. Sensors and Actuators B: Chemical, 103 (1-2), 104110. DOI:10.1016/j.snb.2004.04.041

46. Ostrick, B., Fleischer, M., Meixner, H., \& Kohl, C.-D. (2000). Investigation of the Reaction Mechanisms in Work Function Type Sensors at Room Temperature by Studies of the Cross-Sensitivity to Oxygen and Water: The Carbonate-Carbon Dioxide System. Sensors and Actuators B: Chemical, 68 (1-3), 197-202. DOI:10.1016/s09254005(00)00429-9
47. Madou, M. J., \& Morrison, S. R. (1989). Chemical sensing with solid state devices. San Diego: Academic Press.

48. Krasovska, M., Gerbreders, V., Sledevskis, E., Gerbreders, A., Mihailova, I., ... \& Ogurcovs, A. (2020). Hydrothermal Synthesis of $\mathrm{ZnO}$ Nanostructures with Controllable Morphology Change. CrystEngComm, 22 (8), 1346-1358. DOI:10.1039/c9ce01556f 